\title{
Propostas alternativas para demonstrações práticas do tema Solos no contexto da Base Nacional Comum Curricular
}

Alternative proposals for Soll practical demonstrations in the context of the National Common Curricular Base

\author{
Bruna Arruda ${ }^{1,2}$, Clécia Cristina Barbosa Guimarães ${ }^{1,3}$, Renata Helena Pin Puccl ${ }^{4}$, Antonio Carlos de Azevedo ${ }^{1,5}$ \\ 1 - Departamento de Clência do Solo, Escola Superior de Agricultura "Luiz de Queiroz" (ESAlQ), Universidade de São Paulo (USP), Piracicaba (SP) \\ 2 - Coordenadora do Programa Ponte Solo na Escola (PPSNE) \\ 3 - Colaboradora do Programa Ponte Solo na Escola (PPSNe) \\ 4 - Professora do Programa de Pós Graduação em Educação da Universidade Metodista de Piracicaba (UNIIMEP). Piracicaba, SP, Brasil. \\ 5 - Professor Associado na ESALQ/USP.

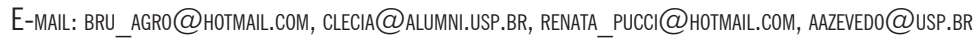

\begin{abstract}
The Programa Ponte Solo na Escola (PPSNE, Soil at School Program) seeks to make aware students, with playful demonstrations, about soil preservation, a non-renewable resource essential to life. Considering that the target audience of the program extends to the whole Brazil, by the internet, the activities of PPSNE were adapted to the National Common Curricular Base (BNCC, Base Nacional Comum Curricular). The objectives were: to analyze the perspective of the BNCC about soils; to reflect on how the topic is approached in the classroom and to suggest demonstrations and different approaches in Brazil. The work examined the usage of the term soil at BNCC and its conceptualization according to Soil Science, with suggestions for demonstrations that can be used in elementary school, as well as contextualizing its approaches throughout of the Brazilian territory, as a way to direct the teaching of soils according to the scholar context and the distinct Brazilian regions.
\end{abstract}

Resumo: 0 Programa Ponte Solo na Escola (PPSNE) busca conscientizar estudantes, por meio de demonstrações lúdicas, sobre a necessidade de preservação do solo, um recurso não renovável essencial à vida. Considerando que o público-alvo do programa se estende a todo 0 Brasil, por meio da internet, as atividades do PPSNE foram adequadas à Base Nacional Comum Curricular (BNCC). Os objetivos foram: analisar a perspectiva da BNCC acerca de solos; refletir sobre o tratamento do tema em sala de aula e sugerir práticas de demonstrações e formas diferenciadas de abordagem no Brasil. 0 trabalho examina 0 uso do termo solo na BNCC e sua conceitualização de acordo com a ciência do solo, com sugestões de demonstrações que podem ser utilizadas no ensino fundamental, bem como uma contextualização de suas abordagens ao longo do território brasileiro, como forma de direcionar 0 ensino de solos de acordo com os contextos escolar e regional brasileiro.

\section{Introdução}

O solo é fundamental à manutenção da vida na Terra (Brady \& Weil, 2010). Um terço dos solos agricultáveis já estão degradados (FAO ITPS, 2015). Esse fato é agravado pela falta de conhecimento da população sobre a temática e quanto mais urbanizado é o meio, maior é o desconhecimento a respeito dos solos, causando uma insensibilidade ao fato de que a sobrevivência do homem na Terra depende do solo (Coelho et al., 2013). É possível interromper e reverter o processo, educando as próximas gerações. Atendendo a essa urgência, proliferam no Brasil programas educacionais, quase sempre sob a denominação de "Solo na Escola", já implantados em mais de 30 universidades (Ramos \& Montino, 2018). Em 2006, a Universidade de trizes curriculares.
Citation/Citação: Arruda, B., Guimarães, C. C. B., Pucci, R. H. P., \& Azevedo, A. C. de. (2021). Propostas alternativas para demonstrações práticas do tema Solos no contexto da Base Nacional Comum Curricular. Terræ Didatica, 17(Publ. Contínua), 1-15, e021016. doi: 10.20396/ td.v17i00.8664132.

Keywords: Playful education. Science. Geography.

Palavras-chave: Educação lúdica. Ciência. Geografia.

Manuscript/Manuscrito:

Received/Recebido: 28/01/2021

Revised/Corrigido: 25/02/2021

Accepted/Aceito: 16/03/2021

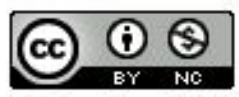

\begin{tabular}{c|c|c|c|c|c|}
\hline C Terrae Didat. & Campinas, SP & v.17 & $1-15$ & $\mathrm{e} 021016$ & 2021 \\
\hline
\end{tabular}

São Paulo [USP], Escola Superior de Agricultura "Luiz de Queiroz" [ESALQ], implantou o Programa Ponte Solo na Escola com esta finalidade. O Programa Ponte Solo na Escola atua de forma presencial e virtual e procura atender aos objetivos educacionais no Brasil, como por exemplo as dire-

Lima (2005), ao analisar os Parâmetros Curriculares Nacionais [PCN] estabelecidos em 1997 no que tange ao tema solos no ensino fundamental, concluiu que há dificuldades na implantação efetiva da diretriz curricular devido a deficiências na formação dos professores e na concepção dos materiais didáticos. Amorim \& Moreau (2003) avaliaram livros didáticos de geografia do ensino médio e observaram que a fragmentação do tema solos 
dificultava seu entendimento. Costa (2012) fez um estudo aprofundado em relação aos PCN, aos materiais didáticos e aos conhecimentos esperados de estudantes de geografia sobre solos e concluiu que o tema não estava efetivamente inserido no currículo do Estado de São Paulo para a disciplina de Geografia.

Em 2015, iniciou-se a elaboração da Base Nacional Comum Curricular [BNCC] com o objetivo de definir um conjunto orgânico e progressivo de aprendizagens essenciais para a Educação Básica, assegurando os direitos de aprendizagem e desenvolvimento (Brasil, 2018). O documento foi disponibilizado ao público para análises e reformulações e, em dezembro de 2018, foi homologado com caráter normativo.

Com base nas versões preliminares da BNCC, Santinelo, Royer, \& Zanatta (2016) avaliaram a abordagem da educação ambiental e constataram que a falta de interdisciplinaridade, que está enraizada nos métodos usuais de ensino, também está presente no documento da BNCC, o que dificulta a formação crítica dos estudantes. Compiani (2018) fez reflexões frente às diferentes versões da BNCC em relação à abordagem de ciências da natureza. Sasseron (2018) entendeu que o documento da BNCC deveria ser tomado como base para a construção do conhecimento, mas que o ensino de ciências deve ser mais amplo, com práticas que facilitem a visualização dos conteúdos.

Assim, o tema Solos na educação básica deve ser baseado no currículo disponível, balizado pela BNCC, mas também na realidade escolar das diferentes regiões brasileiras, uma vez que o conhecimento não deveria ser simplesmente transferido, mas construído e reconstruído conjuntamente com professores e estudantes envolvidos nas atividades. Segundo Muggler, Sobrinho, \& Machado (2006), a construção coletiva e participativa do conhecimento é um dos principais desafios para o Programa de Educação em Solos e Meio Ambiente.

Com base nessas premissas, os objetivos deste estudo foram: i) analisar o documento da BNCC com foco no tema solos; ii) conceituar o tema para ser tratado em sala de aula; iii) sugerir abordagens interdisciplinares utilizando demonstrações; e iv) direcionar abordagens para as regiões do Brasil.

\section{Material e métodos}

A BNCC (Brasil, 2018) foi analisada quanto ao conteúdo de acordo com os métodos propostos por
Lima (1993), com abordagem quanti-qualitativa, contabilizando a palavra solo, conforme Caregnato \& Mutti (2006) e Moraes (1999) e categorizando de acordo com Moraes (1999): i) etapa (educação infantil, ensino fundamental, ou ensino médio); ii) faixa etária, ou ano escolar, e iii) campo de experiências, ou componente curricular. Os assuntos foram examinados nas três grandes áreas do conhecimento da ciência do solo: física, química, e biologia do solo, e os significados captados e intuídos foram descritos a partir das mensagens textuais analisadas, conforme metodologia proposta por Moraes (1999).

Em seguida, foram descritas demonstrações lúdicas capazes de auxiliar no processo de ensino desta temática, e selecionados temas envolvendo solos para elaboração de mapas do território brasileiro: i) temperatura de superfície do solo; ii) susceptibilidade à erosão dos solos; iii) fatores de formação do solo; iv) uso e cobertura do solo e v) classificação dos solos brasileiros. Com esses mapas foi feita uma análise visual de como os temas estão distribuídos nas regiões brasileiras a fim de facilitar uma abordagem individualizada de acordo com a relevância no contexto regional. Os mapas foram confeccionados utilizando a base de dados do Instituto Brasileiro de Geografia e Estatística (IBGE, 2014) e imagens de satélite do ano de 2013 a 2018 fornecidas pelo "United States Geological Survey" (USGS). As imagens foram processadas na plataforma Engine para o mapeamento da temperatura de superfície. A base de dados do IBGE foi processada no software ArcGIS 10.1 e forneceu informações para a construção dos mapas de fatores de formação, classificação, uso e cobertura do solo. Ainda nesse software foi utilizada a metodologia do Instituto Estadual do Meio Ambiente (INEA, 2018) para o mapeamento da susceptibilidade à erosão do solo.

\section{Resultados}

\section{Análise quanti-qualitativa do termo solo na BNCC}

A palavra solo(s) é citada 17 vezes na BNCC. Uma das citações, na área de educação física, refere-se a um aparelho feito de um material elástico que amortece eventuais quedas e ajuda a impulsionar saltos. O termo também apareceu três vezes em textos introdutórios de capítulos e, em tabelas, foi citado duas vezes nos Objetos de Conhecimento e 11 vezes nas Habilidades. 
A BNCC traz o tema solo nas Habilidades exclusivamente no ensino fundamental (EF) sendo citado de maneira direta no componente curricular de ciências, tanto nos anos iniciais $\left(1^{\circ}\right.$ ao $5^{\circ}$ ano) quanto finais ( $6^{\circ}$ ao $9^{\circ}$ ano). O tema também está descrito no componente curricular de geografia e citado em ciências humanas e sociais aplicadas.

Dentre as grandes áreas do conhecimento de solos, a BNCC apresenta maior enfoque na área de física do solo $\left(2^{\circ}, 3^{\circ}, 5^{\circ}\right.$ e $6^{\circ}$ anos $)$. A química do solo é abordada no $3^{\circ}$ ano, a biologia nos $3^{\circ}$ e $5^{\circ}$ anos e os $2^{\circ}, 6^{\circ}, 7^{\circ}$ e $8^{\circ}$ anos envolvem as três áreas (multidisciplinar) (Tab. 1).

$\mathrm{O} 1^{\circ}$ ano do Ensino Fundamental não traz referências ao tema solos (Tab. 1, 2). No $2^{\circ}$ ano, a Habilidade EF02CI08, em ciências, cita o solo como uma das superfícies que é atingida pela radiação solar e envolve conceitos específicos de temperatura do solo. Em paralelo, o componente curricular geografia aborda a Habilidade EF02GE11, com uma discussão sobre o uso e conservação do solo, no campo e na cidade (Tab. 2).

No $3^{\circ}$ ano, o solo aparece na unidade temática "Terra e Universo", no objeto de conhecimento "Uso do solo". Dentre as Habilidades está a EF03CI07, na qual os estudantes devem identificar caraterísticas do planeta Terra em relação à presença de água e solo (Tab. 2). Outra Habilidade (EF03CI09, na Tab. 2) estimula os órgãos dos sentidos dos estudantes e envolve características do solo, como cor, textura, cheiro, tamanho de partículas e permeabilidade. A Habilidade EF03CI10 traz um enfoque voltado à fertilidade e química do solo, em que ele pode ser destacado como fonte de nutrientes para organismos (Tab. 1,2).

$\mathrm{O} 4^{\circ}$ ano não menciona o termo solo em suas Habilidades (Tab. 1, 2). No $5^{\circ}$ ano, a Habilidade EF05CI03, dentro de ciências, envolve a importância da cobertura vegetal, o impacto da gota de chuva e a erosão, relacionados a conceitos conservacionistas do solo (Tab. 1, 2).

No $6^{\circ}$ ano, a Habilidade EF06GE05 traz conceitos de intemperismo e de fatores de formação do solo (Tab. 1, 2). A EF06GE10 trata das dife- rentes formas de uso do solo (Tab. 2). No $7^{\circ}$ ano, a EF07CI07 traz o conceito de ecossistemas, que pode ser relacionado com os diversos tipos de solo do território brasileiro e como o solo pode afetar a vida nos diferentes ambientes, dentro do tema específico de ecologia de solo (Tab. 1, 2). No $8^{\circ}$ ano, a EF08GE18 relaciona o uso e ocupação de solos da África e América (Tab. 2). O solo não é mencionado nas Habilidades do $9^{\circ}$ ano.

Em relação à área de ciências humanas e sociais aplicadas, o texto da BNCC cita brevemente o uso do solo, no tópico de Território e Fronteira, trazendo a percepção de práticas de diferentes sociedades.

\section{Discussão}

A utilização de experimentos e demonstrações como complemento da educação é um instrumento poderoso de ensino. A vivência científica desperta habilidades nos estudantes, como a capacidade de relacionar teoria e prática, sendo emancipatória na formação de sujeitos que pensam a sociedade de forma coerente (Fortuna, 2016). A ineficiência no canal de comunicação entre ciência e as práticas pedagógicas (Nunes, 2008) torna a prática científica no ambiente escolar tímida, mesmo nos dias atuais. No caso do ensino de solo, em particular,

\begin{tabular}{c|c|c|c|c|c}
\hline (C) Terrae Didat. & Campinas, SP & v.17 & $1-15$ & $\mathrm{e} 021016$ & 2021 \\
\hline
\end{tabular}




\begin{tabular}{|c|c|c|c|}
\hline $\begin{array}{l}\text { Código al- } \\
\text { fanumérico }\end{array}$ & Ano & $\begin{array}{l}\text { Componente } \\
\text { curricular }\end{array}$ & Habilidade \\
\hline * & $1^{\mathrm{o}}$ & * & $*$ \\
\hline (EF02CI08) & $2^{o}$ & Ciências & $\begin{array}{l}\text { Comparar o efeito da radiação solar (aquecimento e reflexão) em diferentes } \\
\text { tipos de superfície (água, areia, solo, superfícies escura, clara e metálica etc.). }\end{array}$ \\
\hline (EF02GE11) & $2^{\circ}$ & Geografia & $\begin{array}{l}\text { Reconhecer a importância do solo e da água para a vida, identificando seus } \\
\text { diferentes usos (plantação e extração de materiais, entre outras possibili- } \\
\text { dades) e os impactos desses usos no cotidiano da cidade e do campo. }\end{array}$ \\
\hline (EF03CI07) & $3^{\circ}$ & Ciências & $\begin{array}{l}\text { Identificar características da Terra (como seu formato esférico, a presença } \\
\text { de água, solo etc.), com base na observação, manipulação e comparação de } \\
\text { diferentes formas de representação do planeta (mapas, globos, fotografias etc.). }\end{array}$ \\
\hline (EF03CI09) & $3^{\circ}$ & Ciências & $\begin{array}{l}\text { Comparar diferentes amostras de solo do entorno da escola com base em car- } \\
\text { acterísticas como cor, textura, cheiro, tamanho das partículas, permeabilidade } \\
\text { etc. }\end{array}$ \\
\hline (EF03CI10) & $3^{\circ}$ & Ciências & $\begin{array}{l}\text { Identificar os diferentes usos do solo (plantação e extração de materiais, } \\
\text { dentre outras possibilidades), reconhecendo a importância do solo para a } \\
\text { agricultura e para a vida. }\end{array}$ \\
\hline$*$ & $4^{\circ}$ & $*$ & $*$ \\
\hline (EF05CI03) & $5^{\circ}$ & Ciências & $\begin{array}{l}\text { Argumentar sobre a importância da cobertura vegetal para a manutenção do } \\
\text { ciclo da água, a conservação dos solos, dos cursos de água e da qualidade } \\
\text { do ar atmosférico. }\end{array}$ \\
\hline (EF06GE05) & $6^{\circ}$ & Geografia & Relacionar padrões climáticos, tipos de solo, relevo e formações vegetais. \\
\hline (EF06GE10) & $6^{\mathrm{o}}$ & Geografia & $\begin{array}{l}\text { Explicar as diferentes formas de uso do solo (rotação de terras, terraceamen- } \\
\text { to, aterros etc.) e de apropriação dos recursos hídricos (sistema de irrigação, } \\
\text { tratamento e redes de distribuição), bem como suas vantagens e desvanta- } \\
\text { gens em diferentes épocas e lugares. }\end{array}$ \\
\hline (EF07CI07) & $7^{\mathrm{o}}$ & Ciências & $\begin{array}{l}\text { Caracterizar os principais ecossistemas brasileiros quanto à paisagem, à quan- } \\
\text { tidade de água, ao tipo de solo, à disponibilidade de luz solar, à temperatura } \\
\text { etc., correlacionando essas características à flora e fauna específicas. }\end{array}$ \\
\hline (EF08GE18) & $8^{\circ}$ & Geografia & $\begin{array}{l}\text { Elaborar mapas ou outras formas de representação cartográfica para analisar as } \\
\text { redes e as dinâmicas urbanas e rurais, ordenamento territorial, contextos cul- } \\
\text { turais, modo de vida e usos e ocupação de solos da África e América. }\end{array}$ \\
\hline$*$ & $9^{\circ}$ & $*$ & $*$ \\
\hline
\end{tabular}

Nota: * solo não citado na BNCC

este quadro tem se modificado rápida e significativamente pela multiplicação das iniciativas do tipo Solo na Escola pelo país. O Programa Ponte Solo na Escola aborda a teoria aplicada em cada ano da educação fundamental, de acordo com os temas e habilidades determinadas pela BNCC, direcionando demonstrações que podem auxiliar os docentes no processo de ensino-aprendizagem.

\section{Abordagens interdisciplinares sobre solos utilizando demonstrações: Educação Infantil}

Apesar da BNCC não contemplar o tema solo para a educação infantil, alguns objetivos de aprendizagem podem ser atingidos utilizando o solo, como a pintura com tintas de solo (Fig. 1A).
Como proposto por Goulart (2006), por meio da arte, a criança tem ampliadas as possibilidades de desenvolvimento de habilidades de criar, criticar e sentir. Os solos oferecem grande variedade de pigmentos, contemplando os Objetivos de Aprendizagem EI01TS02, para bebês (zero a 1 ano e 6 meses) e EI02TS02, para crianças de 1 ano e 7 meses a 3 anos e 11 meses (Tab. 3). O professor deve propor situações que levem a criança a aprimorar suas expressões e percepções, observar, ver, sentir, tocar e fazer (Nascimento \& Tavares, 2009). Essa atividade permite um primeiro contato da criança com o solo e a desconstrução do solo como algo inerte, sujo e sem valor. A tinta de solo pode ser produzida pelo professor a partir da mistura de solo, água e cola branca, como descrito por Batista \& Arruda (2020).

\begin{tabular}{c|c|c|c|c|c|}
\hline C Terrae Didat. & Campinas, SP & v.17 & $1-15$ & e21016 & 2021 \\
\hline
\end{tabular}



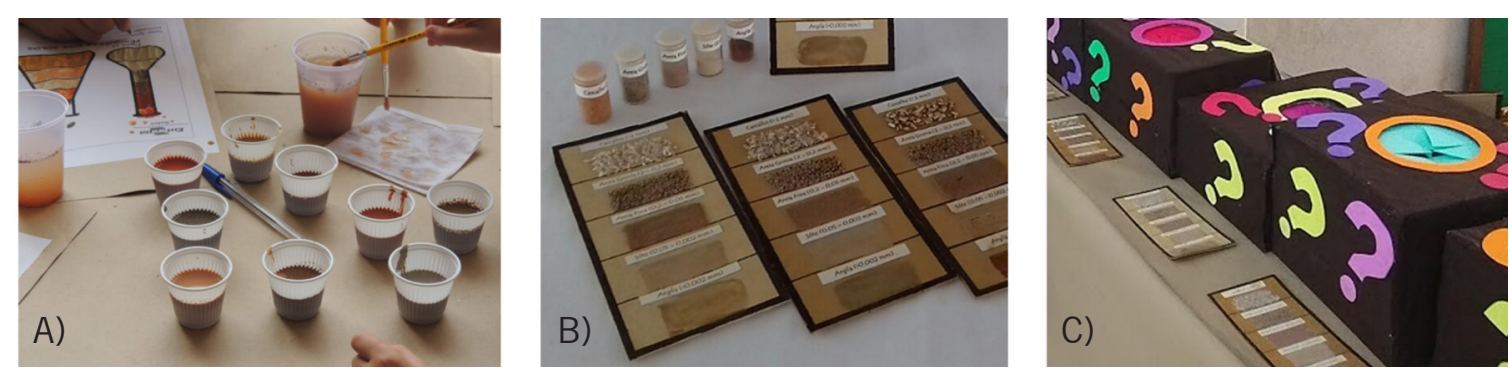

Figura 1. Demonstrações sugeridas para ensino de solo segundo as diretrizes da Base Nacional Comum Curricular. A) Pintura com tinta de solo; B) Cartela textural; C) Cheiro às cegas. Fonte: acervo cedido pelo Programa Ponte Solo na Escola (PPSNE)

O desenvolvimento cognitivo se dá na interação da criança com o meio, objetos e pessoas, descobrindo o mundo. Assim, a análise tátil do solo exercita a percepção de diferentes classes texturais e da diferença no tamanho de partículas, que podem ser obtidas passando uma amostra de solo através de peneiras com malhas de diferentes aberturas. As diferentes porções de solo obtidas podem ser coladas em papelão ou cartolina, possibilitando a criação de uma cartela textural que permite compreender que o solo é formado por partículas de diferentes tamanhos e causam diferentes sensibilidades ao tato (Fig. 1B). A atividade pode ser utilizada também para atender à Habilidade EI02TS02. Além disso, é possível trabalhar com o olfato, utilizando o cheiro do solo (Fig. 1C).

\section{Abordagens interdisciplinares sobre solos utilizando demonstrações: Ensino Fundamental - anos iniciais}

$\mathrm{O}$ tema solo pode ser trabalhado no $1^{\circ}$ ano, mesmo não existindo referência direta da BNCC, pois nos conteúdos de ciências, a Habilidade EF01CI01 traz a competência de comparar características de diferentes materiais, discutindo sua origem e modos de descarte ambientalmente coerentes (Tab. 3). Resíduos orgânicos podem ser usados para produzir o composto a ser aplicado em hortas escolares, permitindo que os estudantes tenham papel ativo na aprendizagem, tão essencial em processos de alfabetização prática e científica (Penick,1998). Alternativamente, pode-se criar um ambiente visível aos estudantes onde haja solo, minhocas e compostos orgânicos (minhocário) e observar a decomposição realizada por esses organismos do solo (Fig. 2A).

No $2^{\circ}$ ano, o solo é abordado envolvendo o efeito da radiação solar sobre as superfícies, nos aspectos de energia, calor e condutividade. Quando a radiação atinge o solo, o balanço de calor (absorção, reflexão e irradiação) se manifesta através da temperatura. Esta dinâmica afeta todos os processos que ocorrem no solo. A temperatura varia ao longo do perfil do solo, decrescendo em profundidade, e é influenciada pela cor, umidade e composição das partículas do solo. Solos com cores escuras tendem a apresentar temperaturas mais elevadas. A presença ou ausência de cobertura no solo, bem como seu tipo (vegetal ou plástica, por exemplo) também afeta a temperatura. Esta, por sua vez, interfere em diversos componentes e processos do solo havendo a necessidade de uma abordagem interdisciplinar.

Para o $2^{\circ}$ ano, o Programa Ponte Solo na Escola propõe a simulação da incidência de raios solares através de lâmpadas de infravermelho e o monitoramento da temperatura ao longo do perfil de solo (Fig. 2B). Os contrastes regionais podem ser trabalhados com os mapas de temperatura de superfície do Brasil (Fig. 3A), levando os estudantes a entenderem como as condições climáticas interferem não somente nas atividades dos organismos, mas também causam modificações nos solos. É importante relacionar esse fenômeno à latitude, ressaltando a importância da cartografia (Castro, Soares \& Quaresma, 2015).

Ainda no $2^{\circ}$ ano, é destacada a importância do solo e água para a vida e seus impactos no cotidiano da cidade e campo. A organização de debates pode ajudar a desenvolver o senso crítico dos estudantes, envolvendo, por exemplo, discussões sobre como o solo não-urbano afeta a vida nas cidades, tendo como base de argumentação o abastecimento de alimentos e o regime hídrico (secas e enchentes). A agropecuária alimenta a população mundial, rural e urbana, e essa atividade depende de recursos não renováveis, do solo e da água, que sem manejo adequado, não atenderão a demanda de alimento. Outra discussão importante diz respeito à impermeabilidade do solo nas cidades e à necessidade de áreas verdes. Poucos cidadãos entendem que a utilização desordenada do solo urbano causa tragédias urbanas como enchentes e desmoronamentos. Essas abordagens permitem que os estudantes ajam

\begin{tabular}{c|c|c|c|c|c}
\hline (C) Terrae Didat. & Campinas, SP & v.17 & $1-15$ & e021016 & 2021 \\
\hline
\end{tabular}


Tabela 3. Objetivos de Aprendizagem e Desenvolvimento ou Habilidades que não citam o termo solos descritas na Base Nacional Comum Curricular (BNCC) (Brasil, 2018), mas que permitem que esta temática seja abordada em sala de aula

\begin{tabular}{|c|c|c|c|}
\hline $\begin{array}{l}\text { Código } \\
\text { alfanumé- } \\
\text { rico }\end{array}$ & Faixa etária/ Ano & $\begin{array}{l}\text { Campo de } \\
\text { experiências/ } \\
\text { Componente } \\
\text { curricular }\end{array}$ & Objetivos de Aprendizagem e Desenvolvimento / Habilidade \\
\hline \multicolumn{4}{|r|}{ Educação Infantil } \\
\hline EI01TS02 & $\begin{array}{l}\text { Bebês (zero a } 1 \\
\text { ano e } 6 \text { meses) }\end{array}$ & $\begin{array}{l}\text { Traços, sons, } \\
\text { cores e formas }\end{array}$ & $\begin{array}{l}\text { Traçar marcas gráficas, em diferentes suportes, usando instru- } \\
\text { mentos riscantes e tintas. }\end{array}$ \\
\hline EI02TS02 & $\begin{array}{l}\text { Crianças bem } \\
\text { pequenas } \\
\text { (1 ano e } 7 \text { meses } \\
\text { a } 3 \text { anos e } 11 \\
\text { meses }\end{array}$ & $\begin{array}{l}\text { Traços, sons, } \\
\text { cores e formas }\end{array}$ & $\begin{array}{l}\text { Utilizar materiais variados com possibilidades de manipulação } \\
\text { (argila, massa de modelar), explorando cores, texturas, superfícies, } \\
\text { planos, formas e volumes ao criar objetos tridimensionais. }\end{array}$ \\
\hline \multicolumn{4}{|r|}{ Ensino Fundamental } \\
\hline EF01CI01 & $1^{\mathrm{o}}$ & Ciências & $\begin{array}{l}\text { Comparar características de diferentes materiais presentes em } \\
\text { objetos de uso cotidiano, discutindo sua origem, os modos como } \\
\text { são descartados e como podem ser usados de forma mais cons- } \\
\text { ciente. }\end{array}$ \\
\hline EF04CI01 & $4^{\circ}$ & Ciências & $\begin{array}{l}\text { Identificar misturas na vida diária, com base em suas propriedades } \\
\text { físicas observáveis, reconhecendo sua composição. }\end{array}$ \\
\hline EF04CI07 & $4^{\circ}$ & Ciências & $\begin{array}{l}\text { Verificar a participação de microrganismos na produção de ali- } \\
\text { mentos, combustíveis, medicamentos, entre outros }\end{array}$ \\
\hline EF04GE11 & $4^{\circ}$ & Geografia & $\begin{array}{l}\text { Identificar as características das paisagens naturais e antrópicas } \\
\text { (relevo, cobertura vegetal, rios etc.) no ambiente em que vive, } \\
\text { bem como a ação humana na conservação ou degradação dessas } \\
\text { áreas. }\end{array}$ \\
\hline EF04CI06 & $4^{\circ}$ & Ciências & $\begin{array}{l}\text { Relacionar a participação de fungos e bactérias no processo de } \\
\text { decomposição, reconhecendo a importância ambiental desse pro- } \\
\text { cesso. }\end{array}$ \\
\hline EF05CI01 & $5^{\circ}$ & Ciências & $\begin{array}{l}\text { Explorar fenômenos da vida cotidiana que evidenciem proprie- } \\
\text { dades físicas dos materiais - como densidade, condutibilidade } \\
\text { térmica e elétrica, respostas a forças magnéticas, solubilidade, res- } \\
\text { postas a forças mecânicas (dureza, elasticidade etc.), entre outras. }\end{array}$ \\
\hline EF05CI07 & $5^{\circ}$ & Ciências & $\begin{array}{l}\text { Justificar a relação entre o funcionamento do sistema circulatório, } \\
\text { a distribuição dos nutrientes pelo organismo e a eliminação dos } \\
\text { resíduos produzidos. }\end{array}$ \\
\hline EF05CI08 & $5^{\circ}$ & Ciências & $\begin{array}{l}\text { Organizar um cardápio equilibrado com base nas características } \\
\text { dos grupos alimentares (nutrientes e calorias) e nas necessidades } \\
\text { individuais (atividades realizadas, idade, sexo etc.) para a manu- } \\
\text { tenção da saúde do organismo. }\end{array}$ \\
\hline EF05MA19 & $5^{\circ}$ & Matemática & $\begin{array}{l}\text { Resolver e elaborar problemas envolvendo medidas das grande- } \\
\text { zas comprimento, área, massa, tempo, temperatura e capacidade, } \\
\text { recorrendo a transformações entre as unidades mais usuais em } \\
\text { contextos socioculturais. }\end{array}$ \\
\hline EF05MA21 & $5^{\circ}$ & Matemática & $\begin{array}{l}\text { Reconhecer volume como grandeza associada a sólidos geométri- } \\
\text { cos e medir volumes por meio de empilhamento de cubos, utili- } \\
\text { zando, preferencialmente, objetos concretos. }\end{array}$ \\
\hline EF06GE09 & $6^{\mathrm{o}}$ & Geografia & $\begin{array}{l}\text { Elaborar modelos tridimensionais, blocos-diagramas e perfis } \\
\text { topográficos e de vegetação, visando à representação de elementos } \\
\text { e estruturas da superfície terrestre. }\end{array}$ \\
\hline EF08CI02 & $8^{\circ}$ & Ciências & $\begin{array}{l}\text { Construir circuitos elétricos com pilha/bateria, fios e lâmpada ou } \\
\text { outros dispositivos e compará-los a circuitos elétricos residenciais. }\end{array}$ \\
\hline EF09CI13 & $9^{\circ}$ & Ciências & $\begin{array}{l}\text { Propor iniciativas individuais e coletivas para a solução de proble- } \\
\text { mas ambientais da cidade ou da comunidade, com base na análise } \\
\text { de ações de consumo consciente e de sustentabilidade bem-suce- } \\
\text { didas }\end{array}$ \\
\hline
\end{tabular}


A)

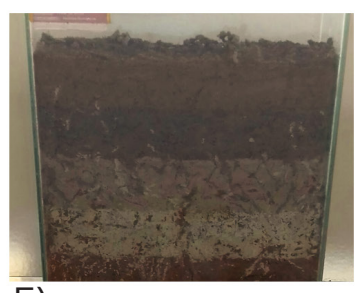

E)

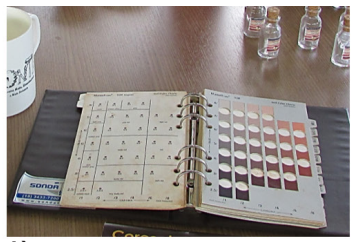

I)

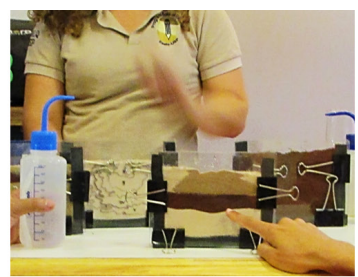

M)

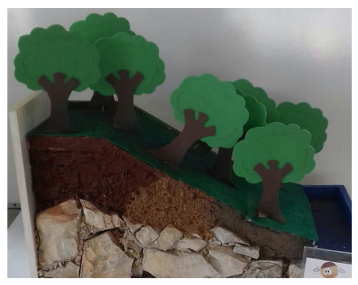

B)

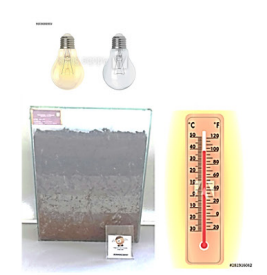

F)

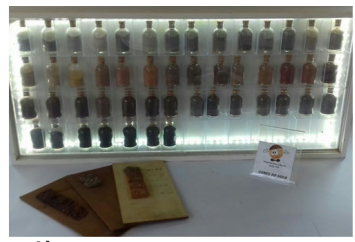

J)

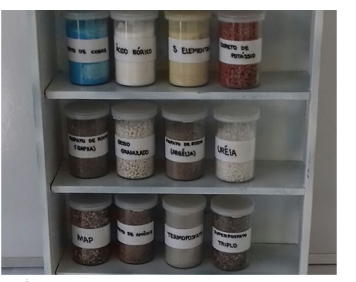

N)

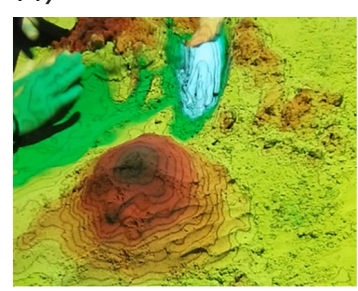

C)

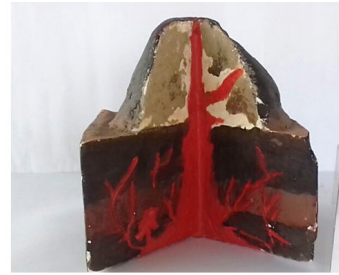

G)

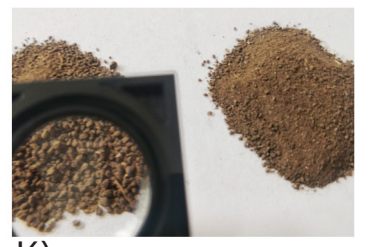

K)

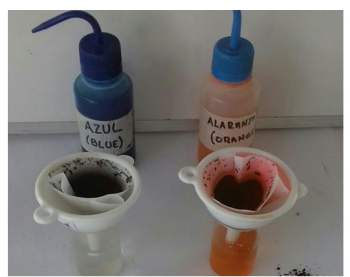

0)

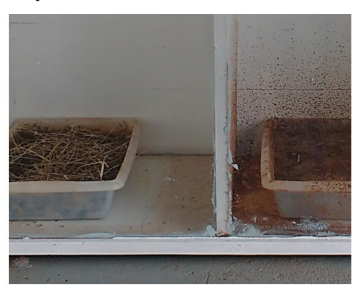

D)

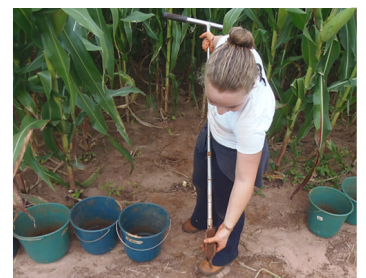

H)

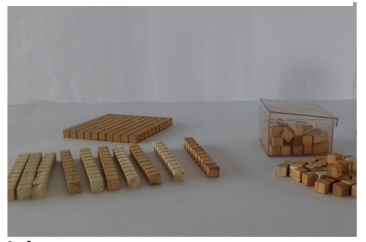

L)

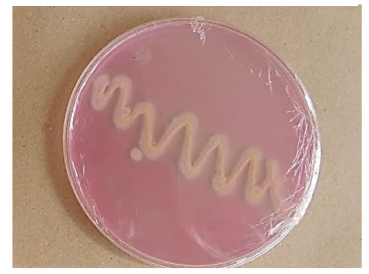

P)

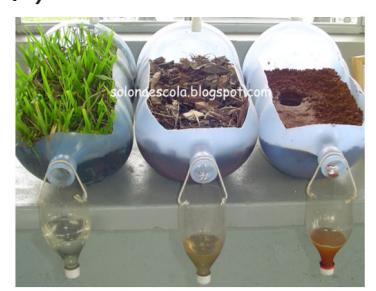

Figura 2. Demonstrações sugeridas para ensino de solo segundo as diretrizes da Base Nacional Comum Curricular. A) Minhocário; B) Aquecimento do solo; C) Perfil de um vulcão; D) Amostragem de solo; E) Cartela de Munsell; F) Vitrine de cores de solo; G) Solos com diferentes texturas; H) Cubos de madeira para ensino do tamanho das partículas do solo; I) Placas de acrílico preenchidas com diferentes tipos de solo submetidos a frente de molhamento; J) Mostruário de fertilizantes; K) Capacidade de troca de cátions (CTC) do solo; L) Placa de Petri com fungo; M) Maquete de relevo; N) Caixa de areia dinâmica; O) Impacto da gota de chuva; P) Escorrimento superficial. Fonte: acervo cedido pelo Programa Ponte Solo na Escola (PPSNE)

como transformadores da realidade e adquiram conhecimentos que visam à melhoria da qualidade ambiental para as gerações presentes e futuras (Marques \& Xavier, 2019).

A partir do $3^{\circ}$ ano, espera-se que o estudante compreenda as relações entre solo, água e seres vivos nos fenômenos de escoamento de água, erosão e fertilidade do solo, em ambientes rurais e urbanos, e que reconheça causas e consequências da poluição da água, do ar e do solo (Brasil, 2018). A habilidade de identificar as caraterísticas da Terra, em relação à presença de água e solo ganham importância nesse nível de escolaridade. É importante ressaltar que, de acordo com a Teoria dos Fatores de Formação do Solo (Jenny, 1941), o solo só existe no planeta Terra, pois, para que haja solo, é obrigatório a presença de vida. Sugere-se a utilização de uma representação de um perfil de vulcão durante os trabalhos sobre as características da Terra (Fig. 2C). Esse perfil pode ser construído a partir da utilização de argila de modelar e, com o auxílio de professores de geografia, podem ser desenhadas, com pincel e tinta, estruturas presentes na crosta terrestre. Uma compreensão insatisfatória dos estudantes a respeito do planeta Terra durante esta etapa resultará em formulação de conceitos equivocados já nos primeiros anos, levando o estudante a basear seu entendimento da dinâmica do planeta apenas no senso comum (Oliveira, Bacci, Soares, \& Silva, 2012).

Outra habilidade do $3^{\circ}$ ano é a comparação entre diferentes amostras de solo em função dos sentidos, como cor e textura, favorecendo o desenvolvimento cognitivo a partir de percepções senso-

\begin{tabular}{c|c|c|c|c|c}
\hline (C) Terrae Didat. & Campinas, SP & v.17 & $1-15$ & $\mathrm{e} 021016$ & 2021 \\
\hline
\end{tabular}




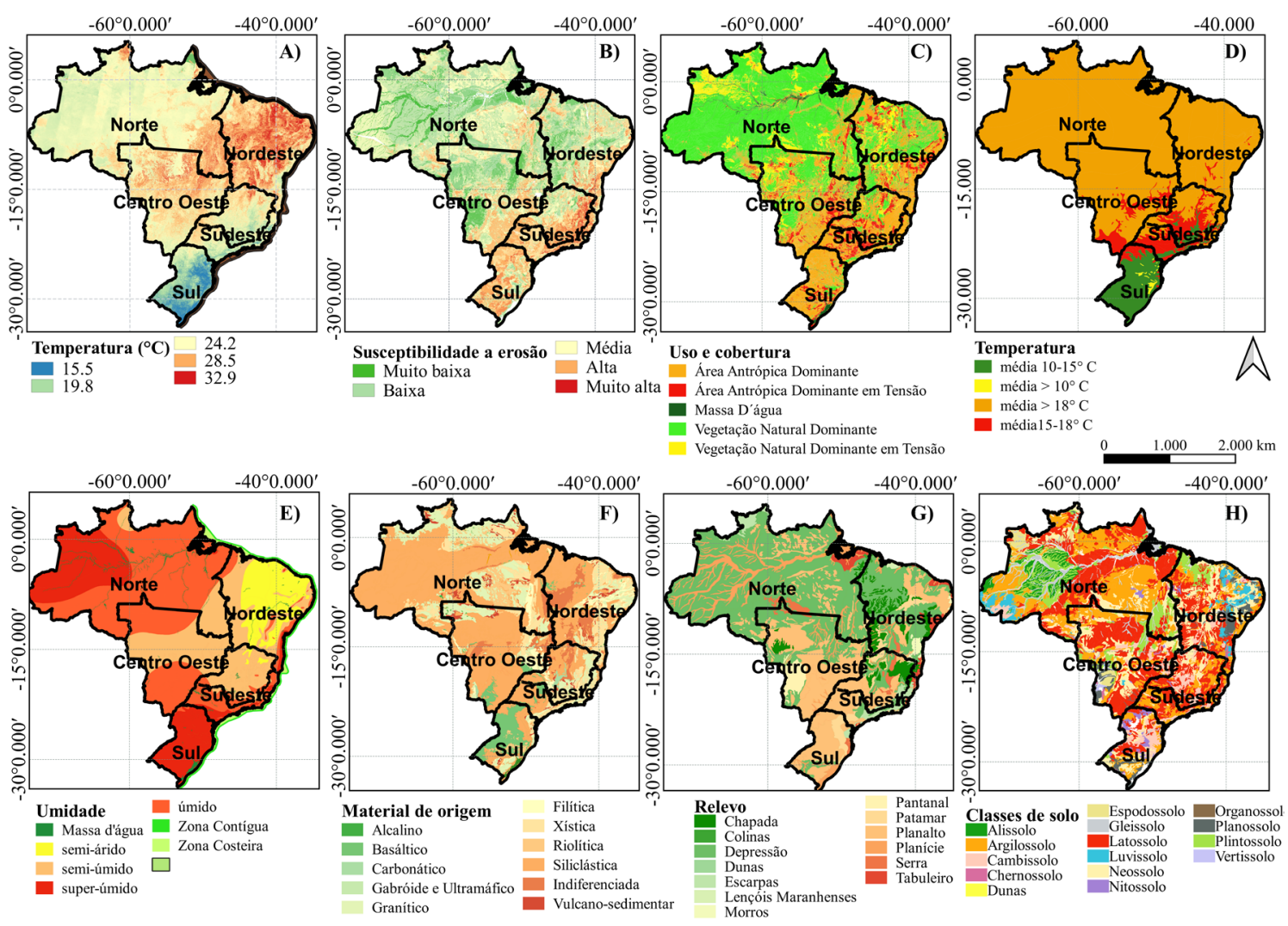

Figura 3. Mapas dos fatores de formação dos solos ( $A, C, D, E, F)$ e suas consequências $(B, H)$ nas regiões brasileiras: A) Temperatura de superfície do solo (Fonte: Landsat 8 (2013 - 2010)); B) Susceptibilidade a erosão (Fonte: INEA, 2018); C) Uso e Cobertura do solo (Fonte: IBGE, 2014); D) Temperatura (Fonte: IBGE, 2014) ; E) Umidade (Fonte: IBGE, 2014); F) Material de Origem (Fonte: IBGE, 2014); G) Relevo (Fonte: IBGE, 2014); e H) Classes de solos (Fonte: IBGE, 2014).

riais (Aranha, 2016), que são objetos de estudo da física e morfologia do solo. A amostragem do solo é uma etapa fundamental para sua devida caracterização, sendo possível levar os estudantes a campo ou no entorno da escola e amostrar o solo com uma pá, enxada ou trado (Fig. 2D).

A análise visual e tátil do solo informa o material de origem, usos e finalidades do solo. A cor do solo é avaliada com a carta de Munsell (Fig. 2E), e varia com a umidade, por isso, as amostras devem ser comparadas com teor de umidade semelhante. As cores variam também de acordo com a sua composição mineral e orgânica. Nas regiões tropicais, como no Brasil, o óxido de ferro é um componente importante na formação da cor. O hidróxido de ferro goethita $(\mathrm{FeO}(\mathrm{OH}))$ possui coloração amarela e o óxido de ferro hematita $\left(\mathrm{Fe}_{2} \mathrm{O}_{3}\right)$, vermelha. $\mathrm{O}$ terceiro componente importante na cor é a matéria orgânica, que contribui com tons de preto. Solos alagados e posteriormente drenados, normalmente próximos de rios, tendem a apresentar cor acinzentada, devido à ausência de formas oxidadas de ferro.
A carta de cores de Munsell é de alto custo e difícil de ser encontrada, mas é possível o professor utilizar o site do sistema Munsell, via internet. Outra possibilidade é montar um mostruário com diversos solos e discutir as causas da diversidade de cores (Fig. 2F). A pintura com tintas feitas com solo (Fig. 1A) também é uma atividade relacionada a cores do solo.

Outra característica física importante do solo é a sua textura, que é resultado da proporção entre partículas de diferentes tamanhos: argila $(<0,002$ $\mathrm{mm})$; silte $(0,002-0,02 \mathrm{~mm})$; areia fina $(0,02-0,2$ $\mathrm{mm})$; areia grossa $(0,2-2,0 \mathrm{~mm})$, de acordo com a escala adotada pela Sociedade Brasileira de Ciência do Solo. A separação das frações pode ser feita por peneiras e a proporção das frações é expressa na forma de porcentagem, ou mais corretamente em $\mathrm{g} \mathrm{kg}^{-1}$. Os solos com maior porcentagem de argila são denominados de argilosos, e os com maior proporção de areia são chamados de arenosos. As diferenças nos tipos de solo em função da textura podem ser observadas com a cartela textural de

\begin{tabular}{c|c|c|c|c|c}
\hline (C) Terrae Didat. & Campinas, SP & v.17 & $1-15$ & $\mathrm{e} 021016$ & 2021 \\
\hline
\end{tabular}


solos (Fig. 1B). A sensação visual e tátil permitirá aos estudantes compreenderem as diferenças existentes entre elas. Com a ajuda de uma lupa é possível observar que partículas de solo de natureza diferente (formato, brilho e cor) se acumulam em determinadas classes de tamanho (Fig. 2G).

A textura define a área superficial específica (ASE), que se refere à soma das áreas expostas de cada partícula (argila, silte ou areia) em relação à sua massa (ou volume) e, portanto, se relaciona à reatividade de cada partícula no solo. Solos arenosos tem menor ASE, pois grânulos grandes possuem menor área externa exposta, comparativamente à argila que apresenta grande ASE. A ASE pode ser representada com cubos de madeira de diferentes tamanhos, fazendo analogia com as partículas de solo (Fig. 2H). Aqui destacam-se os conceitos matemáticos de medidas que só são realmente compreendidos pela criança quando ela própria começa a realizar medidas, sendo que esse processo se inicia na infância, mas é realizado durante toda a vida (Pozebon, 2014).

A textura do solo também é determinante para diversas outras propriedades, como a permeabilidade à água. De modo geral, solos arenosos são mais permeáveis do que os argilosos, porque partículas maiores geram poros maiores que permitem a passagem de água com maior volume e velocidade. As partículas de argila, pelo tamanho reduzido, ocupam mais os poros e restringem a passagem de água. Para mostrar o efeito da textura do solo na permeabilidade da água, podem ser utilizadas placas de acrílico transparentes, preenchidas com solo de diferentes texturas. Água gotejada na superfície permite observar a frente de molhamento, seu tamanho e formato em função da textura, volume de água e tempo (Fig. 2I). Para a melhor compreensão da importância da textura na passagem de água e retenção de materiais no solo, é necessário que o docente domine os fundamentos de matemática, física e química, pois a interdisciplinaridade é essencial no processo de ensino e aprendizagem da complementaridade e inter-relações entre os conteúdos (Lenoir, 1998).

Ainda no $3^{\circ}$ ano, o tema solo na agricultura também é discutido, podendo ser abordadas questões sobre sua fertilidade e química, destacando-o como fonte de nutrientes para as plantas. Os elementos químicos presentes no solo são classificados em relação à quantidade exigida pelas plantas, onde os macro e micronutrientes são exigidos em maiores e menores quantidades, respectivamente.
A quantidade de nutrientes no solo é analisada em laboratório e o resultado é avaliado por profissionais, como engenheiro agrônomo ou florestal, que identificam a deficiência ou excesso de um ou mais elementos no solo. No processo agrícola, as raízes das plantas interagem com o solo e retiram os nutrientes necessários para o crescimento vegetal. Em seguida, esse material vegetal ficará disponível para alimentação humana (urbana e rural), carregando consigo os nutrientes do solo, criando um elo entre o campo e a cidade e demonstrando que o solo é a fonte indireta de nutrientes aos humanos. Desta forma, o estudante deve perceber que o solo é fundamental nos ecossistemas terrestres e para sua própria alimentação (Lima, 2005).

Os nutrientes retirados pelas plantas necessitam ser repostos para manter a produtividade do solo. Para repor os nutrientes é calculado a quantidade e o tipo de fertilizantes a serem aplicados, podendo ser sólidos ou líquidos, minerais ou orgânicos. Os docentes podem utilizar um mostruário de fertilizantes para visualizar as principais formulações disponíveis no mercado (Fig. 2J).

Após aplicado o fertilizante no solo, os nutrientes de cargas positivas (cátions) podem ficar retidos nas cargas negativas das argilas do solo. A propriedade é chamada Capacidade de Troca de Cátions (CTC). Os nutrientes que ficam retidos eletrostaticamente na CTC do solo podem rapidamente reverterem-se para a forma solúvel (na água do solo) e abastecerem as necessidades dos organismos. O mecanismo faz do solo um reservatório temporário de nutrientes, evitando que parte dos nutrientes seja lixiviada pelas águas de drenagem para os reservatórios subterrâneos, e para longe do alcance das raízes. Para demonstrar a CTC do solo, o Programa Ponte Solo na Escola conta com uma demonstração mais lúdica que utiliza reagentes de cores azul (azul de metileno) e laranja (alaranjado de eosina) que serão adicionados às amostras de solo acondicionadas em filtros de papel (Fig. 2K). As cargas dos elementos são representadas por cores, o que facilita o entendimento do fenômeno por estudantes do $3^{\circ}$ ano. Com a demonstração, o corante azul possui carga positiva $(+)$ e o laranja, negativa (-). Como o solo tem carga predominantemente negativa (-), quando a solução azul atravessa uma porção de solo, os cátions corantes ficam retidos no solo e a solução sai incolor no outro extremo da porção de solo. A solução laranja, por possuir carga negativa, não é retida pelo solo e sai alaranjada na outra extremidade.

\begin{tabular}{c|c|c|c|c|c}
\hline (C) Terrae Didat. & Campinas, SP & v.17 & $1-15$ & $\mathrm{e} 021016$ & 2021 \\
\hline
\end{tabular}


O solo não é abordado para o $4^{\circ}$ ano na BNCC, mas algumas demonstrações do Programa Ponte Solo na Escola podem auxiliar no desenvolvimento de habilidades dos estudantes de forma prática, pois o solo é um tema interdisciplinar. Para tratar da identificação de misturas na vida diária, com base em suas propriedades físicas observáveis (Habilidade EF04CI01) (Tab. 3), podem ser utilizadas peneiras para separação das diferentes frações do solo (Fig. 2G). Para verificar a participação de microrganismos na produção de alimento, com o enfoque na agricultura (Habilidade EF04CI07) (Tab. 3), podem ser utilizadas placas de Petri com meios de cultura com crescimento de microrganismos isolados a partir do solo (Fig. 2L). A explicação sobre a produção de meios de cultura caseiros pode ser obtida no material elaborado por Arruda, Pereira, \& Diogo Filho (2020). A maquete de relevo e a caixa de areia de realidade aumentada (Fig. $2 \mathrm{M}$ e $2 \mathrm{~N}$ ) podem ser utilizadas para identificar características das paisagens e atender a Habilidade EF04GE11 (Tab. 3). O relevo pode ser representado em material isopor e, com a ajuda dos professores de geografia, podem ser incluídos diferentes elementos da paisagem. A caixa de areia de realidade aumentada é uma demonstração mais complexa que não depende apenas do professor para construí-la e, sim, de toda a comunidade escolar. São necessários caixotes de madeira, projetor, suporte para os caixotes, câmera Kinect e um computador contendo o software específico. Se houver interesse da escola na produção desse material, os gestores podem entrar em contato com os autores deste trabalho para melhores informações. Não havendo condições de produzir uma caixa dessa, o professor pode entrar em contato com o Programa Solo na Escola mais próximo de sua comunidade e marcar uma visita ou utilizar aplicativos de realidade aumentada que podem ser manuseados diretamente no celular. $\mathrm{O}$ minhocário (Fig. 2A) e os microrganismos do solo (Fig. 2L) podem ser utilizados para complementar a Habilidade EF04CI06 (Tab. 3), que descreve o processo de decomposição.

Nos $5^{\circ}$ e $6^{\circ}$ anos, há um enfoque para a preservação, formação e usos dos solos de diferentes origens. Os estudos das características dos solos estão voltados à compreensão da sua profunda integração com o regime de chuvas, com a formação do relevo, vegetação e com as decorrências da ocupação humana ao longo do território brasileiro
(Brasil, 2018).

No $5^{\circ}$ ano é abordada a conservação do solo, destacando a importância da cobertura vegetal. Em um evento de chuva, as gotas de água se formam em grande altitude e com alta energia potencial. Durante sua queda em direção ao solo, a energia potencial é transformada em energia cinética e dissipada no impacto com a superfície, e se o solo estiver descoberto, causa o desprendimento de suas partículas e seu salpicamento. A presença de cobertura vegetal no solo o protege deste impacto e facilita a infiltração da água e seu armazenamento nos poros do solo para períodos de ausência de chuva. A demonstração do impacto da gota de chuva sobre solo descoberto e com cobertura morta pode ser utilizada (Fig. 2O). O professor pode realizar a demonstração dispondo amostras de solo em bandejas, cobrir uma das amostras com material orgânico morto e simular um evento de chuva, com regador ou algo semelhante. Na situação sem cobertura vegetal, o impacto da gota de chuva é capaz de causar o desprendimento e salpicamento das partículas do solo. Por outro lado, quando o solo está coberto, o impacto da gota é amortecido pela cobertura, protegendo o solo. Essa demonstração pode também ser utilizada para auxiliar na Habilidade EF05CI01 (Tab. 3) e explorar fenômenos da vida cotidiana que evidenciem propriedades físicas dos materiais como respostas a forças mecânicas.

A vegetação tem papel importante não apenas como cobertura protetora, mas também como participante do ciclo da água no ambiente. Uma parcela de água da chuva é retida pela vegetação e quanto maior for a superfície de folhagem, maior a área de retenção da água durante a precipitação (Tucci \& Clarke, 1997). A planta retira água do solo para a manutenção de suas atividades vitais e libera essa água para a atmosfera a partir da transpiração.

O processo de infiltração é desfavorecido em solos compactados, devido à destruição de grande parte de seus poros. A diminuição da infiltração aumenta o escoamento superficial da água, que pode evoluir para processos de erosão hídrica, que carrega as partículas para os cursos hídricos. Se o volume de sedimentos depositados for muito grande, o canal do curso de água diminui sua seção hidráulica (assoreamento) e transborda durante chuvas mais fortes, causando enchentes mais frequentes e catastróficas. A compactação também pode ser uma barreira ao crescimento das raízes.

\begin{tabular}{c|c|c|c|c|c}
\hline (C) Terrae Didat. & Campinas, SP & v.17 & $1-15$ & $\mathrm{e} 021016$ & 2021 \\
\hline
\end{tabular}


O entendimento da conservação do solo requer uma visão holística. Os estudantes devem perceber que vários elementos do sistema estão interligados e interdependentes. Para isso, é preciso construir pontes entre os diferentes saberes, em contraposição à visão fragmentada (Nascimento \& Souza, 2014).

Para demonstrar aos estudantes de $5^{\circ}$ ano a importância da conservação do solo, pode ser utilizada a demonstração de escorrimento superficial (Fig. 2P), em três situações: 1) vaso com cobertura vegetal viva; 2) vaso com cobertura vegetal morta; e 3) vaso sem cobertura vegetal, todos em declives iguais. Quando a chuva é simulada, observa-se perda de solo através de potes na extremidade mais baixa do vaso, que coletam o solo transportado. No solo sem cobertura, muitas partículas são carreadas e a aparência final da água coletada é escura. No solo com cobertura viva observa-se menor carreamento de partículas e a água coletada é quase transparente, havendo pouca perda de solo devido ao efeito das raízes.

No estudo da conservação do solo em nível nacional, pode-se utilizar o mapa de susceptibilidade à erosão do território brasileiro (Fig. 3B). Este mapa indica que a região norte é a que apresenta a menor susceptibilidade a erosão, devido à sua cobertura de floresta (Fig. 3C). As regiões mais susceptíveis à erosão são Sul e Sudeste, por estarem mais sujeitas às atividades antrópicas.

Em uma abordagem interdisciplinar da conversão de unidade usuais de temperatura, no ensino da matemática para os estudantes de $5^{\circ}$ ano (Habilidade EF05MA19) (Tab. 3), pode ser utilizada a demonstração das variações de temperatura ao longo do perfil do solo (Fig. 2B). Além disso, para auxiliar a Habilidade EF05MA21 (Tab. 3), ainda no componente de matemática, cuja descrição é o reconhecimento de volume como grandeza associada a sólidos geométricos e a medição de volumes por meio de empilhamento de cubos, utilizando, preferencialmente, objetos concretos, pode-se utilizar os cubos de madeira para o ensino de tamanho de partículas do solo (Fig. 2H). Esse material dá uma ideia da área de exposição de acordo com o tamanho das partículas do solo e as implicações desses tamanhos na atividade e interação entre as partículas do solo. Nas Habilidades EF05CI07 e EF05CI08 do $5^{\circ}$ ano é possível utilizar o mostruário de fertilizantes (Tab.3, Fig. 2J), abordando-os como fonte indireta de nutrientes aos humanos, envolvendo a nutrição do organismo e hábitos alimentares.

\section{Abordagens interdisciplinares sobre solos utilizando demonstrações: Ensino Fundamental - anos finais}

No $6^{\circ}$ ano, a abordagem do solo envolve fatores que agem diretamente na decomposição das rochas (intemperismo) e formação do solo (pedogênese). A formação do solo é um dos conteúdos mais dinâmicos para ser aplicado à educação fundamental (Santos \& Guimarães, 2010). O material de origem é determinante no solo formado, representado pelas rochas metamórficas, sedimentares e magmáticas. Os fatores climáticos são fundamentais na transformação da rocha em solo, através de mecanismos físicos (dilatação e contração, aquecimento e resfriamento) e reações químicas, dependentes da temperatura, que aceleram as reações no solo, e da presença e quantidade de água líquida. O relevo também tem papel importante, pois controla a distribuição de calor (exposição solar) e água na paisagem. Áreas mais planas imprimem menor velocidade de escorrimento da água na superfície, favorecendo a infiltração. A água infiltra no solo e proporciona transformações em maior profundidade, gerando perfis de solo mais profundos. Em relevos mais íngremes, a água escorre com maior velocidade e atinge áreas mais baixas. Assim, o tempo de permanência da água é pequeno, desfavorecendo a infiltração e ocorrem solos mais rasos. A ação biológica também tem seu papel, pois o sistema radicular das plantas, bem como os micro, meso e macroorganismos excretam moléculas orgânicas, absorvem nutrientes, movimentam partículas, fixam carbono e nitrogênio da atmosfera para o solo, contribuindo para o desenvolvimento das propriedades do solo. Outro fator a ser considerado é o tempo, já que para formar 1 centímetro de solo são necessários de centenas a milhares de anos.

Os professores podem fazer uso de diferentes demonstrações envolvendo os cinco fatores: 1) material de origem: mostruário de rochas sedimentares, metamórficas e magmáticas (Fig. 4A); 2) relevo e 3) clima: maquete do relevo (Fig. 2M); 4) tempo: estágios de formação do solo que pode ser construído em material de acrílico ou caixas de papelão divididas em compartimentos (Fig. 4B); e 5) organismos: insetário, minhocário e placa de Petri com fungo (Fig. 4C, 3A, 3L). Tanto a maquete do relevo (Fig. 2M) quanto os monólitos (Fig. 4D), que são perfis de solo coletados in situ e que trazem todas as suas características naturais, podem ser utilizados para atender a Habilidade EF06GE09 (Tab. 3), para elaborar modelos tridimensionais, blocos- 


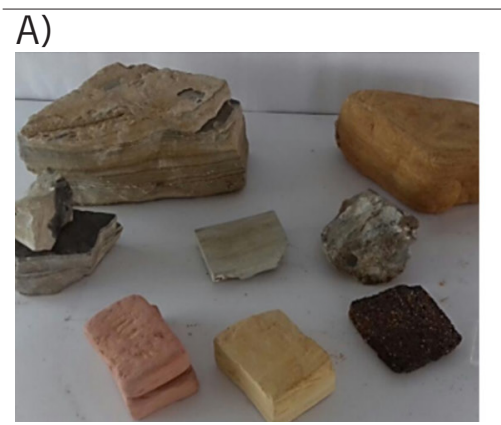

D)

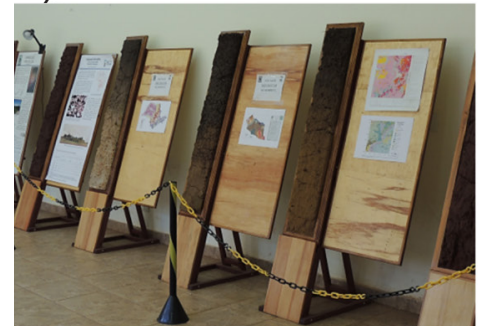

B)

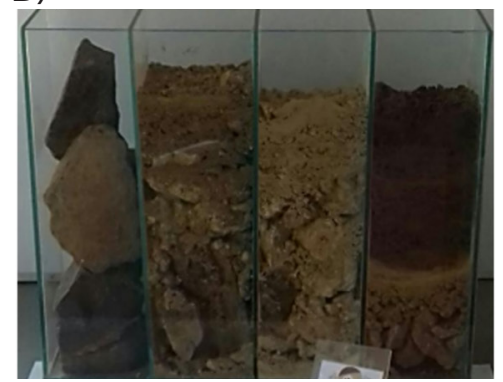

E)

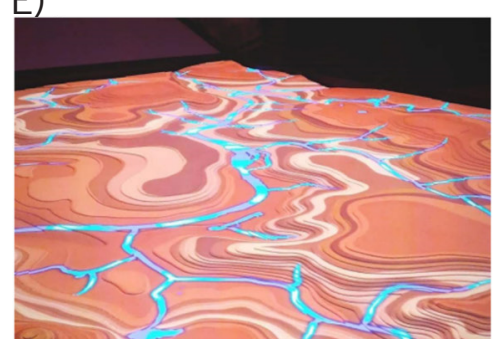

C)

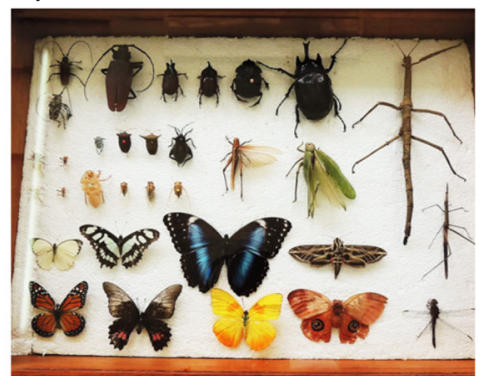

F)

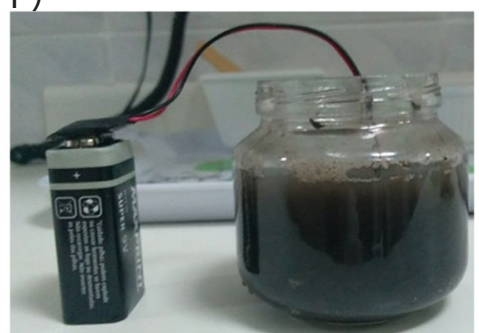

Figura 4. Demonstrações sugeridas para ensino de solo segundo as diretrizes da Base Nacional Comum Curricular. A) Rochas; B) Estágios de formação do solo; C) Insetário; D) Monólitos; E) Maquete dos rios de Piracicaba; F) Baterias e CTC do solo. Fonte: acervo cedido pelo Programa Ponte Solo na Escola (PPSNE)

-diagramas e perfis topográficos e de vegetação, visando à representação de elementos e estruturas da superfície terrestre.

Os docentes podem complementar o conteúdo utilizando mapas. Os fatores de formação temperatura e umidade do ar (clima), rochas (material de origem) e relevo irão influenciar, ao longo do tempo, no tipo de solo que irá se formar. No Brasil, esses fatores se diversificam, o que resulta em grande diferenciação dos tipos de solos (Fig. 3D, E, F, G e H). A granulometria e cor são próprias de cada solo e, com base nessas e em outras características, os solos são classificados, de acordo com o Sistema Brasileiro de Classificação de Solos (SiBCS). Observando a distribuição dos tipos de solos no Brasil, observa-se que nas regiões em que há maior umidade e temperatura e o relevo é plano, os solos são, em geral, mais profundos, como os representados pelas classes Latossolo e Argissolo. É possível aprofundar a discussão e relacionar o intemperismo com os principais tipos de solo de cada região, uso e cobertura desses solos. Além disso, para demonstrar como as propriedades do solo variam em profundidade, podem ser utilizados os monólitos (Fig. 4D).

Ainda no $6^{\circ}$ ano há uma retomada do tema usos do solo, com um enfoque no manejo e na sua interação com a água. É importante destacar que este trecho da BNCC traz diversos termos da área de solo de maneira confusa, tendo reflexos em sala de aula. De acordo com Falconi (2004), alguns temas relacionados ao solo têm sido apresentados nos livros didáticos de forma fragmentada e desconectada. Com isso, os professores, por desconhecimento, não conseguem identificar as falhas nesses materiais. O termo rotação de terra, por exemplo, é utilizado como uma prática agrícola, porém essa terminologia não é muito utilizada. Esta prática pode estar se referindo à movimentação do solo agrícola, porém essa terminologia não é muito utilizada. Esta prática pode estar se referindo à movimentação de aração e gradagem, cujo objetivo é destorroar a camada superficial do solo para favorecer sua mistura com os insumos aplicados, homogeneizar a distribuição de sementes e facilitar emergência de plântulas, controle de plantas não cultivadas, etc. Entretanto, essas práticas prejudicam a estrutura natural do solo, bem como a proteção exercida pela deposição da palha dos cultivos anteriores, tornando o solo mais susceptível a perdas pelos processos erosivos. Práticas agrícolas adequadas e conservacionistas são realizadas, na verdade, a partir do plantio direto, adotado desde 1972 no Brasil. Este não usa o revolvimento do solo e as culturas subsequentes são semeadas sobre os restos da cultura anterior. Além de preservar a agregação do solo, a cobertura vegetal constante protege o solo contra o impacto da gota de chuva e recicla nutrientes pela decomposição da palhada. No entanto, a prática de rotação está mais associada à rotação de culturas, que busca intercalar cultivos sucessivos de diversos grupos de plantas, com vários benefícios às culturas agrícolas, como ciclagem de nutrientes, interrupção do ciclo de doenças de 
plantas cultivadas, aumento da riqueza de espécies de organismos no solo e no entorno.

Outros termos que precisam ser melhor esclarecidos são terraceamento e aterro, os dois citados na Habilidade EF06GE10 como formas de uso do solo. O termo terraceamento é uma prática conservacionista que visa reduzir os impactos da erosão no solo. Nela, a inclinação do terreno a ser cultivado é modificada utilizando curvas de nível e terraços, construídos para armazenar ou desviar a água, evitando que o escorrimento superficial adquira energia cinética suficiente para carregar partículas e provocar erosão hídrica. A caixa de areia de realidade aumentada (Fig. 2N) torna possível observar a dinâmica de aspectos de paisagens e a relação entre curvas de nível e terraceamento. Já o termo "aterro" é utilizado na engenharia civil para designar área onde o saibro é depositado para nivelamento e/ou elevação e, na engenharia ambiental, como local destinado para depósito de resíduos sólidos gerados pela atividade humana, devendo ser bem planejado, uma vez que este processo envolve a liberação de chorume, que pode causar sérios danos ambientais.

Os cubos de madeira para ensino do tamanho das partículas do solo podem ser utilizados para atender a Habilidade EF06MA24, cuja descrição é resolver e elaborar problemas que envolvam as grandezas, como o volume (sólidos formados por blocos retangulares), sem uso de fórmulas, inseridos, sempre que possível, em contextos oriundos de situações reais e/ou relacionadas às outras áreas do conhecimento (Fig. 2H).

No $7^{\circ}$ ano, o solo é relacionado aos diferentes ecossistemas brasileiros, que tem particularidades em relação à paisagem, clima, quantidade de água disponível, disponibilidade de luz solar, temperatura, fauna e flora. Todos esses fatores, bióticos e abióticos, são determinantes na formação e evolução do solo, e são também por ele influenciados. Para demonstrar os ecossistemas, pode-se utilizar o minhocário (Fig. 2A) e o insetário (Fig. 4C), que trazem organismos com ciclo completo, ou parte dele, no solo e destacam o efeito biológico sobre o solo. Uma abordagem interessante é a problematização das questões ambientais, considerando os diferentes ecossistemas brasileiros. Campos (1999) conseguiu envolver estudantes em questões socioambientais, tornando-os agentes modificadores da realidade.

A abordagem do solo no $8^{\circ}$ ano está relacionada ao uso e ocupação de solos da África e Américas. As diferentes características do solo revelam suas aptidões de uso e ocupação. Solos com alta fertilidade ou com características físicas desejáveis ao plantio são primariamente ocupadas para uso na agricultura. É importante ressaltar durante a discussão do tema, que o uso intensivo do solo pode provocar o esgotamento de suas capacidades produtivas, gerando áreas degradadas, mas que com o manejo adequado das propriedades físicas, químicas e biológicas é possível recuperar algumas destas áreas, tornando-as produtivas novamente e, consequentemente, diminuindo a pressão para a expansão de áreas agrícolas sobre áreas com vegetação nativas. Atlas rurais podem ser utilizados como material complementar didático no processo de aprendizagem. Além disso, podem ser exploradas maquetes de cidades, como a dos rios de Piracicaba localizada na estação do Programa Ponte Solo na Escola e observado o uso e ocupação do solo da região em função dos rios (Fig. 4E).

O uso de mapas pode ser uma ferramenta promissora na abordagem dos conteúdos, pois permite uma compreensão visual mais concreta do conteúdo abordado. Ao visualizar o mapa de uso e cobertura dos solos é possível perceber que as regiões Sul e Sudeste concentram o uso agrícola, enquanto a região Norte apresenta a vegetação natural como dominante (Fig. 3C). O docente pode relacionar essas diferenças regionais com o clima e a geologia e apontar aspectos econômicos e ambientais de cada região relacionados ao uso e cobertura do solo e sua ocupação (Fig. 3D, E, F e G). As áreas em vermelho no mapa de uso e cobertura representam as atividades antrópicas que degradaram bastante o solo. Concentradas na região sudeste, as áreas degradadas resultam de intensa atividade agrícola e da poluição associada à intensa urbanização e aumento populacional (Fig. 3C). Os professores também podem discorrer sobre as melhores práticas de manejo agrícola para reduzir os impactos aos solos e explicar os benefícios da cobertura vegetal para a manutenção das características do solo e de todo o ecossistema, demonstrando como as áreas mais susceptíveis à erosão são as mesmas em que há atividade agrícola intensa (Fig. 3B e C).

Para estudantes de $8^{\circ}$ ano, atendendo a Habilidade EF08CI02 (Tab. 3) de construir circuitos elétricos com pilha/bateria, fios e lâmpada ou outros dispositivos, o Programa Ponte Solo na Escola oferece uma demonstração da presença de cargas no solo (CTC) envolvendo o uso de baterias (Fig. 4F).

Para o $9^{\circ}$ ano, atendendo a Habilidade EF09CI13 (Tab. 3) de propor iniciativas individu-

\begin{tabular}{c|c|c|c|c|c}
\hline (C) Terrae Didat. & Campinas, SP & v.17 & $1-15$ & $\mathrm{e} 021016$ & 2021 \\
\hline
\end{tabular}


ais e coletivas para a solução de problemas ambientais, sugere-se incentivar propostas que envolvam recurso naturais não-renováveis, como água e solo.

\section{Considerações finais}

Observou-se, neste estudo, que a abordagem do tema solos na BNCC é predominantemente utilitarista e não ecossistêmica e que, apesar de o tema solos estar presente na BNCC e englobar as três áreas fundamentais da Ciência do Solo, há uma dissociação e um desbalanço entre elas, sendo os aspectos físicos mais enfatizados que os outros dois. A desconexão entre as grandes áreas de estudo do solo deve ser evitada, pois a física, a química e a biologia dos solos são indissociáveis na prática, sendo sempre necessário fazer uma relação entre elas nos seus diversos temas.

Constatou-se que o uso da palavra solo, em alguns trechos da BNCC, é confuso e, em outros, não está de acordo com o uso correto da terminologia, o que pode gerar imprecisões conceituais entre professores e de entendimento por parte dos estudantes. Observou-se, também, que a temática Solos está ausente na Educação Infantil, nos $1^{\circ}$, $4^{\circ}$, e $9^{\circ}$ anos do Ensino Fundamental, e no Ensino Médio, e está mais concentrada no $3^{\circ}$ ano do ensino fundamental. Entretanto, mesmo nos anos em que o solo não é mencionado na BNCC, devido à interdisciplinaridade da temática, é possível estabelecer uma relação do tema com outros conteúdos.

Iniciativas de educação em solos estão se multiplicando por todo o país, sediadas em universidades e órgãos de pesquisa, e podem, a exemplo do Programa Ponte Solo na Escola ESALQ/USP, oferecer apoio para o avanço do tema na próxima revisão da BNCC. Recomenda-se ao Ministério da Educação buscar apoio junto à Sociedade Brasileira de Ciência do Solo, que mantém um catálogo de todas as iniciativas no Brasil, contemplando educação em solos.

\section{Referências}

Amorim, R. R., \& Moreau, A. (2003). Avaliação do conteúdo da ciência do solo em livros didáticos de geografia do ensino médio. GEO-UERJ, Número Especial, 74-81.

Aranha, M. L. (2016). A importância da ludicidade e da psicomotricidade para a educação infantil. João Pessoa: Universidade Federal da Paraíba. 33p. (Trab. Concl. Curso).

Arruda, B., Pereira, N. A., \& Diogo Filho, G. J. (2020). Organismos do Solo. In: Arruda, B., Frozza, M.
V. C., \& Azevedo, A. C. de (Orgs.). 2020. Solo sob diferentes percepções: Brasil e Colômbia. São José: Márcia Vidal Candido Frozza, p. 7-11.

Batista, A. M, \& Arruda, B. (2020). Fazendo tinta com solo. In: Arruda, B., Frozza, M. V. C., \& Azevedo, A. C. de (Orgs.). 2020. Solo sob diferentes percepções: Brasil e Colômbia. São José: Márcia Vidal Candido Frozza, p. 18-22.

Brady, N. C., \& Weil, R. R. (2010). Elements of the nature and properties of soil. Upper Saddle River: Pearson Prentice Hall. 624p.

Brasil. (2018). Base Nacional Comum Curricular: Educação é a base. Brasília: Ministério da educação [MEC]. URL: http://basenacionalcomum.mec.gov.br/abase/ Acesso 26.03.2021.

Campos, C. E. B. (1999). Em defesa da vida: reflexão sobre o uso inadequado dos recursos naturais. In: Congreso Latinoamericano de la Ciencia del Suelo. Temuco: Universidad de la Frontera, 14, 830p.

Caregnato, R. C. A., \& Mutti, R. (2006). Pesquisa qualitativa: análise de discurso versus análise de conteúdo. Texto Contexto Enferm., 15(4), 679-684. doi: 10.1590/ S0104-07072006000400017.

Castro, C. J. N., Soares, D. A. S., \& Quaresma, M. J. N. (2015). Cartografia e ensino de geografia: o uso de mapas temáticos e o processo de ensino-aprendizagem na educação básica. Boletim Amazônico de Geografia, 2(3), 41-57. doi: 10.17552/2358-7040/bag. v2n3p41-57

Coelho, M. R., Fidalgo, E. C., dos Santos, H. G., Brefin, M. L. M. S., \& Pérez, D. V. (2013). Solos: tipos, suas funções no ambiente, como se formam e sua relação com o crescimento das plantas. In: Moreira, F. M. S., Cares, J. E., Zanetti, R., \& Stumer, S. L. (2013). O ecossistema solo: componentes, relações ecológicas e efeitos na produção vegetal. Lavras, MG: UFLA. 47-62.

Compiani, M. (2018). Comparações entre a BNCC atual e a versão da consulta ampla, item ciências da natureza. Ciências em Foco, 11(1), 91-106.

Costa, R. C. (2012). O ensino de solos na geografia da educação básica no estado de São Paulo e algumas experiências no município de Ourinhos/SP. Ourinhos: Universidade Estadual Paulista. 103p. Trab. Concl. Curso).

Falconi, S. (2004). Produção de material didático para o ensino de solos. Rio Claro: Universidade Estadual Paulista. 115p. (Dissert. Mestrado).

FAO ITPS. (2015). Status of the World's Soil Resources (SWSR). Main Report. Food and Agriculture Organization of the United Nations and Intergovernmental Technical Panel on Soils. Status of the World's Soil Resources: Main Report (fao.org). URL: http:// www.fao.org/3/a-i5199e.pdf.

Fortuna, V. (2016) A relação teoria e prática na educação em Freire. Revista Brasileira de Ensino Superior, 1(2), 64-72. doi: 10.18256/2447-3944/rebes.v1n2p64-72.

Goulart, J. (2006). Trabalhando a arte como conhecimento na educação infantil. Revista de Iniciação Científica, 
4(1), 144-152.

INEA. Instituto Estadual do Meio Ambiente (INEA-RJ). (2018). Atlas dos mananciais de abastecimento público do Estado do Rio de Janeiro: subsídios ao planejamento territorial. Rio de Janeiro: Instituto de Meio Ambiente. 464p.

IBGE. Instituto Brasileiro de Geografia e Estatística. (2014). Base de dados geoambientais. URL: https:// www.ibge.gov.br/geociencias/informacoes-ambientais.html. Acesso 24.09.2020.

Jenny, H. (1941). Factors of soil formation: a system of quantitative pedology. New York. 801p.

Lenoir, Y. (1998). Didática e interdisciplinaridade: uma complementaridade necessária e inconfortável. In: Fazenda, I. (org.). (1998). Didática e Interdisciplinaridade. Campinas: Papirus. p. 45-75.

Lima, M. (1993). Análise de conteúdo: estudo e aplicação. Rev. Logos, 1, 53-58.

Lima, M. R. de. (2005). O solo no ensino de ciências no nível fundamental. Ciência \& Educação (Bauru), 11(3). doi: 10.1590/S1516-73132005000300004.

Marques, R., \& Xavier, C. R. (2019). Análise das inferências na construção do senso crítico numa sequência didática na Educação Ambiental. Revista Cocar, (5), 51-94.

Moraes, R. (1999). Análise de conteúdo. Revista Educação, 22(37), 7-32. doi: 10.1590/S010006832006000400014.

Muggler, C. C., Sobrinho, F. D. A.P., \& Machado, V. A. (2006). Educação em solos: princípios, teoria e métodos. Revista Brasileira de Ciência do Solo, 30(4), 733740. doi: 10.1590/S0100-06832006000400014.

Nascimento, E. S. P., \& Tavares, H. M. (2009). As artes visuais na Educação Infantil: possibilidade real de lúdico e desenvolvimento. Revista Católica, 1(2), 169186.

Nascimento, G. d. S., \& Souza, M. E. S., (2014). Uma visão holística da educação: da fragmentação à totalidade. Interletras, 3(19), 1-11.
Nunes, D. R. (2008). Teoria, pesquisa e prática em Educação: a formação do professor-pesquisador. $E d u$ cação e Pesquisa, 34(1), 97-107. doi: 10.1590/S151797022008000100007.

Oliveira, L. A. S., Bacci, D. d. L. C., Soares, D. B., \& Silva, D. F. (2012). O ensino de Geociências e a formação de professores: experiências de um processo de aprendizagem. In: Anais VIII Encontro Nacional de Pesquisa em Educação em Ciências, São Paulo: ABRAPEC.

Penick, J. E. (1998). Ensinando "alfabetização científica”. Revista Educar, (14), 91-113. doi: 10.1590/01044060.183.

Pozebon, S. (2014). Formação de futuros professores na organização do ensino de matemática para os anos iniciais do ensino fundamental: aprendendo a ser professor em um contexto específico envolvendo medidas. Santa Maria: Universidade Federal de Santa Maria. 195p. (Dissert. Mestrado).

Ramos, M. R., \& Montino, M. A. (2018). Projeto solo na escola: despertando a consciência pedológica, aproximando a universidade da sociedade. Revista Extensão, 2(1), 74-82.

Santinelo, P. C. C., Royer, M. R., \& Zanatta, S. C. (2016). A Educação Ambiental no contexto preliminar da Base Nacional Comum Curricular. Pedagogia em Foco, 11(6), 104-115.

Santos, A. B., \& Guimarães, C. R. P. (2010). A utilização de jogos como recurso didático no ensino de zoologia. Rev. Elétrons. Investig. Educ. Cienc. 5(2).

Sasseron, L. H. (2018). Ensino de Ciências por Investigação e o Desenvolvimento de Práticas: Uma Mirada para a Base Nacional Comum Curricular. Revista Brasileira de Pesquisa em Educação em Ciências, 18(3), 1061-1085. doi: 10.28976/1984-2686rbpec20181831061.

Tucci, C. E. M, \& Clarke, R. T. (1997). Impacto das mudanças da cobertura vegetal no escoamento: revisão. Revista Brasileira de Recursos Hídricos, 2(1), 135-152. 